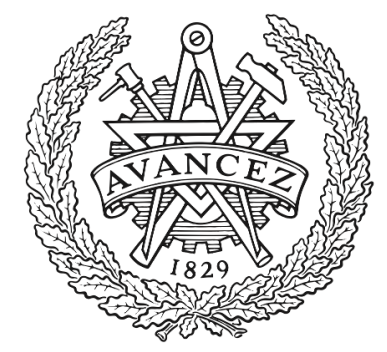

CHALMERS

UNIVERSITY OF TECHNOLOGY

\title{
Wind turbine model validation: Fusion of simulation and measurement data
}

Downloaded from: https://research.chalmers.se, 2023-04-26 11:12 UTC

Citation for the original published paper (version of record):

Stotsky, A. (2014). Wind turbine model validation: Fusion of simulation and measurement data. Proceedings of the Institution of Mechanical Engineers. Part I: Journal of Systems and Control Engineering, 228(9): 734-737. http://dx.doi.org/10.1177/0959651814547442

N.B. When citing this work, cite the original published paper. 


\title{
Proceedings of the Institution of Mechanical Engineers, Part I: Journal of Systems and Control Engineering \\ http://pii.sagepub.com/
}

\section{Wind turbine model validation: Fusion of simulation and measurement data}

Alexander Stotsky

Proceedings of the Institution of Mechanical Engineers, Part I: Journal of Systems and Control Engineering published online 28 August 2014

DOI: $10.1177 / 0959651814547442$

The online version of this article can be found at:

http://pii.sagepub.com/content/early/2014/08/26/0959651814547442

\author{
Published by: \\ (A)SAGE \\ http://www.sagepublications.com
}

On behalf of:

\section{Institution of

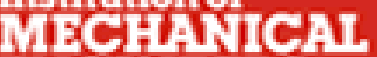 \\ हNलित्रत्र:S}

Institution of Mechanical Engineers

Additional services and information for Proceedings of the Institution of Mechanical Engineers, Part I: Journal of Systems and Control Engineering can be found at:

Email Alerts: http://pii.sagepub.com/cgi/alerts

Subscriptions: http://pii.sagepub.com/subscriptions

Reprints: http://www.sagepub.com/journalsReprints.nav

Permissions: http://www.sagepub.com/journalsPermissions.nav

Citations: http://pii.sagepub.com/content/early/2014/08/26/0959651814547442.refs.html

>> OnlineFirst Version of Record - Aug 28, 2014

What is This? 


\title{
Wind turbine model validation: Fusion of simulation and measurement data
}

Proc IMechE Part I:

J Systems and Control Engineering I-4

C) IMechE 2014

Reprints and permissions:

sagepub.co.uk/journalsPermissions.nav DOI: I0.II77/095965।814547442

pii.sagepub.com

(S)SAGE

\section{Alexander Stotsky}

\begin{abstract}
A new turbine model validation technique that is based on adaptation of look-up tables is described in this article. Simulation results from the VIDYN turbine simulation program and measurements from Big Glenn wind turbine, located outside Gothenburg, Sweden, are used as an input to this new model validation technique. The models of the flapwise bending moment and power coefficient are validated for Big Glenn turbine. Measurement data are acquired during normal turbine operation. Verification results show good agreement between model outputs and measured data. The method allows prediction in a wide range of turbine operating variables, using only few measured points.
\end{abstract}

\section{Keywords}

Wind turbine, model validation, table update method, data fusion

Date received: 3 October 20I3; accepted: 22 July 2014

\section{Introduction}

A number of turbine quantities are estimated using look-up tables that describe mean value model of the turbine. For example, the steady-state operational loads (flapwise and edgewise bending moments) as well as power coefficient can be presented as look-up tables with turbine speed, tip-speed ratio and pitch angle as input variables. Turbine output variables may be calibrated in a wide range of input variables using highfidelity simulation based on GH BLADED, ${ }^{1}$ FAST, ${ }^{2}$ VIDYN $^{3}$ and other programs. However, such models suffer from inaccuracies that are present even in the high-fidelity simulation programs, and therefore may not be good enough for accurate predictions. The accuracy of simulation-based turbine models may be improved using measurement data. The data may be acquired during normal turbine operation. However, measurement data are often available in a certain operating region only. If the wind speed is below rated, the data are available for tip-speed ratio that maximizes energy capture and zero pitch angle. The data that correspond to a certain trajectory of pitch angle at optimal tip-speed ratio are available only if wind speed is above rated. Besides, a measured data set should be properly selected in order to match the steady-state simulation data. For example, low variability in measured data that represent a certain quasi steady-state operating point is required. In addition, the data should be acquired over a relatively large time segment (several minutes) to ensure statistical consistency. Besides, a number of additional requirements may be added to the data selection method. For example, uniformity of the wind speed distribution across the rotor swept area is necessary for validation of the turbine load model. Therefore, the data that correspond to low tilt and yaw nacelle moments should be selected. Such selection essentially reduces a set of measured data points. This motivates the development of a new turbine model validation technique that fuses simulation results with a small set of measured data that are available in a limited operating region.

Steady-state turbine behavior is usually described using look-up tables, and therefore, model validation technique is associated with adaptation of look-up tables. Simulation results are used for pre-calibration of look-up tables and determination of priori dependencies between turbine variables. Statistical quantities of measured variables (mean values and standard deviations) are used for adaptation of look-up tables.

Division of Electric Power Engineering, Department of Energy and Environment, Chalmers University of Technology, Gothenburg, Sweden

\section{Corresponding author:}

Alexander Stotsky, Division of Electric Power Engineering, Department of Energy and Environment, Chalmers University of Technology, Gothenburg SE-4I 2 96, Sweden.

Email: alexander.stotsky@chalmers.se 
Adaptation algorithms of look-up tables were developed and successfully implemented in automotive applications for robustness enhancement. ${ }^{4-6}$ However, adaptation algorithms described in Unland et al., ${ }^{4} \mathrm{Wu}^{5}$ and Zhou et al. ${ }^{6}$ do not allow prediction in a wide range of output variables using a sufficiently small new data set available in a certain operating region only. Algorithms that are suitable for adaptation of look-up tables, using data available in a limited operating region only, were proposed in Stotsky $^{7}$ and further developed in Stotsky. 8,9 According to this concept, the adaptation of look-up table is associated with a motion of the surface in three-dimensional (3D) space. The position and the orientation of the surface in $3 \mathrm{D}$ space change only after adaptation, which, in turn, allows for a prediction for a wide range of output variables. This prediction is possible with few measured points only by taking into account physical dependencies, which are present in the shape of the surface. An adaptation algorithm is constructed so that only the nodes of the lookup table are adapted, whereby the values of the output variable between the nodes are calculated using linear interpolation. Variability in measured data set is accounted via proper assignment of the weighting factors. This concept of adaptation of look-up tables is directly applicable to the turbine model validation.

A new method for turbine model validation that is based on look-up tables that are pre-calibrated using simulation results and adjusted according to measured data is the main contribution of this article. Simulation results from VIDYN simulation program $^{3}$ are fused with measurements taken on Big Glenn wind turbine (see Figure 1) in this model validation method. The models of flapwise bending moment and power coefficient are validated for Big Glenn turbine. Verification results show good agreement between model output and measured data.

The article is organized as follows. General adaptation algorithms of look-up tables are described in

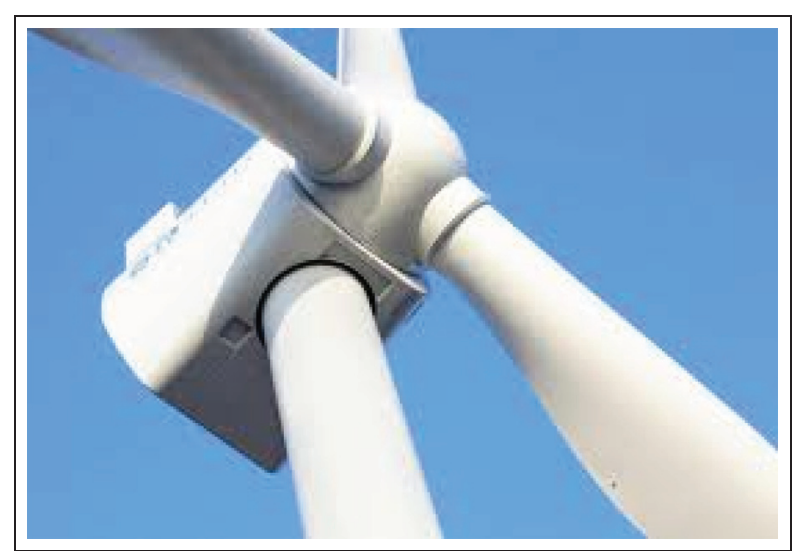

Figure I. Big Glenn wind turbine located outside Gothenburg, Sweden. The turbine was manufactured by GE Wind Energy $\mathrm{GmbH}$ and has rotor diameter of II $2.5 \mathrm{~m}$ with rated power of $4100 \mathrm{~kW}$. section "General adaptation algorithms of look-up tables." Application of this technique to validation of the flapwise bending moment model is presented in section "Validation of the model of flapwise bending moment." The article ends with validation of the turbine power coefficient model in section "Validation of the $C_{p}$ surface" and brief conclusions in section "Conclusion."

\section{General adaptation algorithms of look-up tables}

Suppose that there is a look-up table describing output variable $z$ as a function of two input variables $x$ and $y$. The look-up table is presented as a number of nodes, where the output variable is defined. The values of the output variable between the nodes are calculated using linear interpolation. The problem of adaptation of the look-up table is reduced to calculation of an additive (or multiplicative) compensation term associated with a difference between new measured values of the operating parameter and output the look-up table. The values of this compensation term are added to the nodes of the look-up table. Therefore, the problem of adaptation of the look-up table is reduced to the adaptation of the nodes.

Assume that new measured data $x_{i m}, y_{i m}$ and $z_{i m}$ with the weighting factors $w_{i m}$ are available, where $i=1, \ldots, N$. Note that the weighting factors $w_{i m}$ are assigned according to the accuracy of measured values of the operating parameter. Usually, the weighting factors are inversely proportional to the variances of the measurement noise.

The difference between a value of the parameter $z_{i}$ calculated via a look-up table and new measured value of the parameter $z_{i m}$ is $\varepsilon_{i}=z_{i}-z_{i m}$. Assume that $\varepsilon$ can be approximated with a linear (with respect to parameters) function of two variables, that is

$$
\hat{\varepsilon}=\varphi^{T} \theta
$$

where

$$
\begin{aligned}
& \varphi^{T}=\left[\begin{array}{llll}
1 & x & y & \ldots
\end{array}\right] \\
& \theta=\left[\begin{array}{llll}
a_{0} & a_{1} & a_{2} & \ldots
\end{array}\right]^{T}
\end{aligned}
$$

where $\hat{\varepsilon}$ is an estimate of $\varepsilon$. The parameters $a_{0}, a_{1}$ and $a_{2}$ correspond to adaptation of an offset and the slopes in $x$ and $y$ directions, respectively. The model $\hat{\varepsilon}$ is constructed using a step-wise regression method, where the contribution of each term is reviewed, to ensure that it remains statistically significant. The residuals are compared using the test for equal variances, see Stotsky ${ }^{9}$ for details. The coefficients (equation (3)) are calculated using least-squares method. ${ }^{9}$ As soon as the coefficients and the optimal order of the polynomial are found, the values of the compensation term are calculated and added to the values in the nodes of pre-calibrated lookup table. 


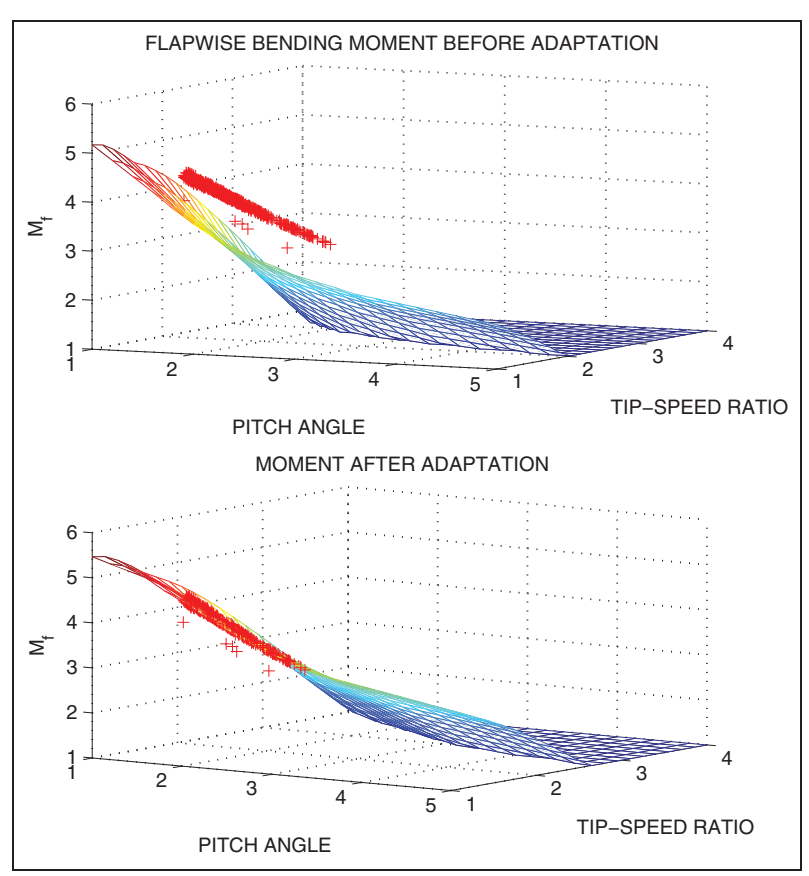

Figure 2. Flapwise bending moment as a function of tip-speed ratio and pitch angle for $15 \mathrm{r} / \mathrm{min}$. Mean values of the flapwise bending moment measured on Big Glenn turbine are plotted with plus signs of a red color. All the variables are presented in normalized units.

\section{Validation of the model of flapwise bending moment}

The steady-state flapwise blade root bending moment can be described as a sandwiched surface (for different turbine speeds) with the tip-speed ratio and blade pitch angle as input variables. Such a surface is pre-calibrated using VIDYN simulation program that describes the model of Big Glenn turbine, and it is plotted in the first subplot of Figure 2 for the turbine speed of $15 \mathrm{r} / \mathrm{min}$. The table is calibrated for a wide range of the values of tip-speed ratio and pitch angle. Measurements of the flapwise bending moment on Big Glenn turbine for the same turbine speed are plotted with plus signs of a red color. These measurements represent the values of the flapwise bending moment averaged over 10-min interval with low standard deviations. Note that the measurement data are available in a limited operating region only. Mismatch between pre-calibrated surface and measured data necessitates adaptation of the surface. The surface, presented in the first subplot of Figure 2, is adapted to the measured data, using adaptation technique described in section "General adaptation algorithms of look-up tables." The slope in the pitch direction is adapted. The result of adaptation is illustrated in the second subplot of Figure 2, where it is shown that almost all measured points are located on the surface. In addition, the profiles of the flapwise bending moment for low turbine speeds and zero pitch angle are also adapted. Finally, the slope of all surfaces,

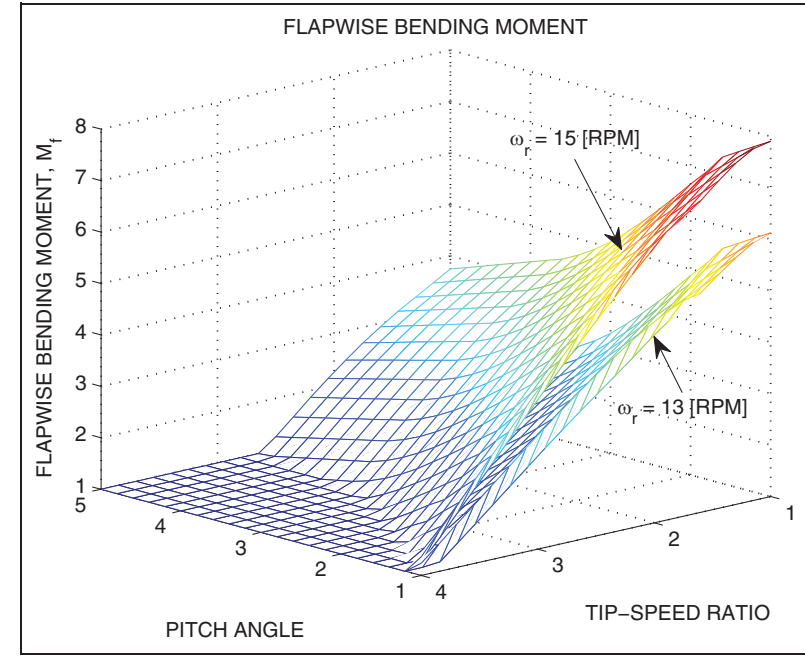

Figure 3. Flapwise bending moment as a function of tip-speed ratio and pitch angle for 13 and $15 \mathrm{r} / \mathrm{min}$. All the variables are presented in normalized units. Similar model of the flapwise bending moment was presented in Stotsky et al. ${ }^{10}$

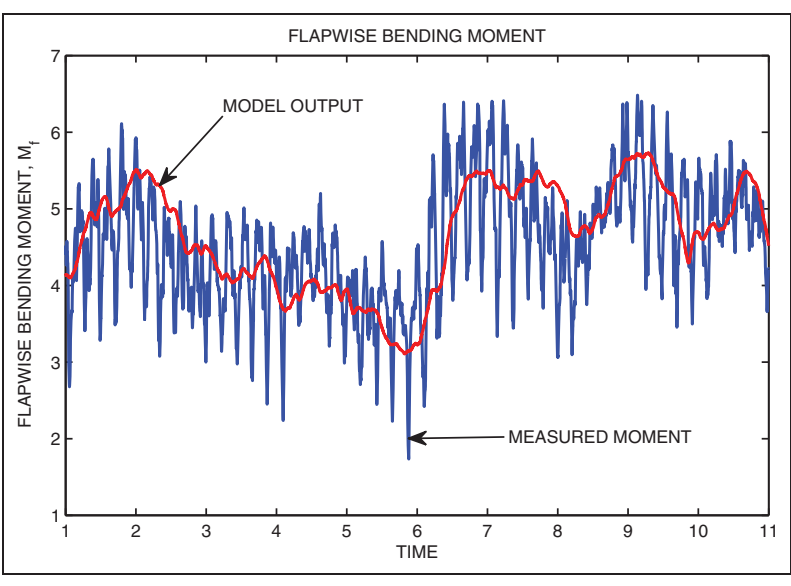

Figure 4. Verification of the model of the flapwise bending moment. Flapwise bending moment measured on Big Glenn wind turbine is plotted with a blue line. The output of the steady-state model of the flapwise bending moment, shown in Figure 3 , is plotted with a red line. All the variables are presented in normalized units.

which represent different turbine speeds, is updated according to the slope of the surface for $15 \mathrm{r} / \mathrm{min}$. Adapted surfaces that represent flapwise bending moment for 13 and $15 \mathrm{r} / \mathrm{min}$ are plotted in Figure 3.

Verification of the model of the flapwise bending moment is presented in Figure 4. Flapwise bending moment, which is measured on Big Glenn wind turbine, is plotted with a blue line. The output of the model, which was adapted according to the procedure described above, is plotted with a red line. This figure shows that the model of the flapwise bending moment, presented as sandwiched surface, is a mean value model that provides accurate prediction of the average values of the moment. 


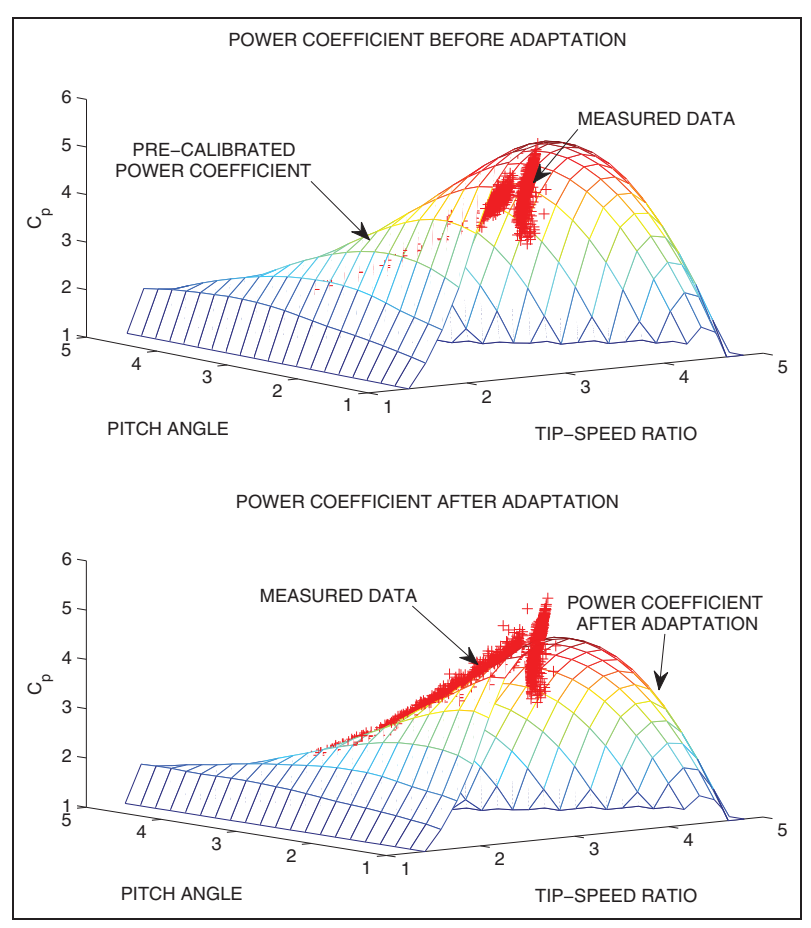

Figure 5. $C_{p}$ surface before and after adaptation. Mean values of the power coefficient measured on Big Glenn turbine are plotted with plus signs of red color. All the variables are presented in normalized units.

\section{Validation of the $C_{p}$ surface}

Power coefficient describes the efficiency of wind turbine and it is presented as a $C_{p}$ surface with tip-speed ratio and pitch angle as input variables. Power coefficient is pre-calibrated using steady-state VIDYN simulations and it is shown in the first subplot of Figure 5. Turbine power was measured on Big Glenn turbine and averaged over 10-min interval. Averaged values of the power coefficient, calculated using mean values of the turbine power with low variances, are plotted in the same subplot with plus signs of a red color. This plot shows that the power coefficient is overestimated in VIDYN simulations. Note that the power coefficient is calculated via turbine applied aerodynamic torque in the VIDYN steady-state simulations. Inaccuracies in estimation of aerodynamic torque have a direct impact on the quality of estimation of the power coefficient. The difference between pre-calibrated surface and measured data is minimized via adaptation. The $C_{p}$ surface is adapted using algorithms described in section "General adaptation algorithms of look-up tables." The result of adaptation is presented in the second subplot of Figure 5, which shows good agreement between measured data and adapted $C_{p}$ surface.

\section{Conclusion}

A new method for turbine model validation based on both simulation and measured data was developed.
Adaptation of the surfaces to measured data, which are acquired during normal turbine operation, is the key idea of this novel model validation method. Validation of the flapwise bending moment and power coefficient for Big Glenn turbine is presented as an example. Good agreement between measured data and model output as a result of adaptation allows prediction of the turbine power and loads for a wide range of turbine operating variables. Validated models are simple enough to be used for control design and simulations.

\section{Acknowledgements}

The author is grateful to Christian Haag from Scandinavian Wind $\mathrm{AB}$ for providing measurement data from Big Glenn wind turbine and to Anders Wickström for providing VIDYN simulation data.

\section{Declaration of conflicting interests}

The author declares that there is no conflict of interest.

\section{Funding}

This work was supported by the Swedish Wind Power Technology Center (SWPTC) and ÅF.

\section{References}

1. Bossanyi E and Quarton D. GH bladed - theory manual. Bristol: Garrad Hassan and Partners Limited, 2003.

2. Jonkman J and Buhl M. FAST user's guide. NREL/EL500-29798, 2005. Golden, CO: National Renewable Energy Laboratory.

3. Ganander $\mathrm{H}$ and Olsson B. VIDYN simuleringsprogram för horisontalaxlade vindkraftverk. Technical report TGR-98-14, 1998. Täby: TG Teknikgruppen AB.

4. Unland S, Heinstein A, Gundlach M, et al. Method for adjusting adaptive programme maps of an adaptive knock control in an internal combustion engine and a method for adjusting the knock control in said engine. US Patent 6,745,749 B2, 2004.

5. Wu G. A table update method for adaptive knock control. SAE paper 2006-01-0607, 2006.

6. Zhou S, Shen X and Chen F. Flow control of air compressor in fuel cell system based on adaptive look-up table algorithm. In: 2010 international conference on electrical and control engineering, Wuhan, China, 25-27 June 2010, pp.3761-3766. New York: IEEE.

7. Stotsky A. Adaptive estimation of the engine friction torque. Eur J Control 2007; 13(6): 618-624.

8. Stotsky A. Data-driven algorithms for engine friction estimation. Proc IMechE, Part D: J Automobile Engineering 2007; 221: 901-909.

9. Stotsky A. Automotive engines: control, estimation, statistical detection. Berlin/Heidelberg: Springer-Verlag, 2009.

10. Stotsky A, Egardt B and Carlson O. An overview of proactive wind turbine control. Energ Sci Eng 2013; 1: 2-11. 